\title{
Novel Indigenous Probiotic Lactobacillus reuteri Strain Produces Anti-biofilm Reuterin against Pathogenic Periodontal Bacteria
}

\author{
Armelia Sari Widyarman ${ }^{1} \quad$ Citra Fragrantia Theodorea ${ }^{2, \odot}$ \\ ${ }^{1}$ Department of Microbiology, Faculty of Dentistry, Trisakti \\ University, West Jakarta, Indonesia \\ ${ }^{2}$ Department of Oral Biology, Faculty of Dentistry, Universitas \\ Indonesia, Indonesia \\ Address for correspondence Armelia Sari Widyarman, PhD, \\ Department of Microbiology, Faculty of Dentistry, Trisakti \\ University, Jln. Kyai Tapa 260, Grogol Jakarta Barat 11440, Indonesia \\ (e-mail: armeliasari@trisakti.ac.id).
}

Eur J Dent 2022;16:96-101.

\author{
Abstract \\ Keywords \\ - biofilm \\ - Lactobacillus reuteri \\ - Porphyromonas \\ gingivalis \\ - reuterin \\ - Treponema denticola
}

Objective The aim of this study was to evaluate the effect of reuterin produced by a novel probiotic strain of Lactobacillus reuteri against periodontal biofilms.

Materials and Methods L. reuteri LC382415 (an indigenous Indonesian strain) was cultured in Man, Rogosa, and Sharpe (MRS) agar in anaerobic conditions for 24 hours. To isolate reuterin, L. reuteri was suspended in $300-\mathrm{mM}$ glycerol in MRS broth and incubated under anaerobic conditions for 3 hours, and the supernatant fraction was filtered. The presence of reuterin was confirmed by sodium dodecyl sulfate-polyacrylamide gel electrophoresis (SDS-PAGE), and its concentration was determined. The effect of reuterin on Porphyromonas gingivalis ATCC 33277 and T. denticola ATCC 35405 biofilms was evaluated using biofilm assays. Biofilms were formed by incubating bacteria in 96 -well microplates for 48 hours. A dose-dependent experiment was performed with reuterin concentrations of $12.5,25,50$, and $100 \mu \mathrm{g} / \mathrm{mL}$ on biofilms. The inhibitory effect was measured at 1, 3, 6, and 24 hours. The biofilm masses were measured at $490 \mathrm{~nm}$. Statistical analysis was using one-way ANOVA.

Results The SDS-PAGE assay confirmed the presence of reuterin ( $52 \mathrm{kDa})$ in the culture supernatant of the $L$. reuteri strain. Reuterin in a concentration as low as $12.5 \mu \mathrm{g} / \mathrm{mL}$ significantly inhibited single- and mixed-species biofilms $(p<0.05)$.

Conclusions This is the first study to demonstrate the promising effect of reuterin isolated from L. reuteri LC382415 against periodontal bacteria. Further studies are warranted to explore the mechanism of this active component.

\section{Introduction}

Periodontitis is considered one of the most prevalent diseases worldwide and the main cause of adult tooth loss. ${ }^{1}$ It is also associated with systemic pathologies, such as cardiovascular disease, obesity, and diabetes. ${ }^{2}$ The etiologic agents of periodontal disease are pathogenic dental plaque biofilms. ${ }^{3}$ Under certain conditions, these biofilms harbor gram-negative

published online July 24, 2021
DOI https://doi.org/

$10.1055 / \mathrm{s}-0041-1731591$ ISSN 1305-7456 bacterial pathogens such as Porphyromonas gingivalis and Treponema denticola, which are closely associated with periodontitis. ${ }^{4}$ These bacteria produce virulence factors that evoke an exacerbated immune-inflammatory response, leading to the destruction of periodontal tissues. Traditionally, periodontitis is treated by mechanical debridement of dental plaque combined with chemical plaque control measures. However, periodontal therapy is costly and may not

(c) 2021. The Author(s).

This is an open access article published by Thieme under the terms of the Creative Commons Attribution License, permitting unrestricted use, distribution, and reproduction so long as the original work is properly cited. (https:// creativecommons. org/licenses/by/4.0/).

Thieme Medical and Scientific Publishers Pvt. Ltd. A-12, 2nd Floor, Sector 2, Noida-201301 UP, India 
be sufficiently effective. Therefore, numerous studies have explored alternative therapies for periodontal disease., ${ }^{5,6}$

Probiotics have been shown to provide numerous benefits as in treatments for various human diseases, including allergic diseases (atopic dermatitis), bacterial vaginosis, urinary tract infections, and gastrointestinal disorders, and as preventives of dental caries. ${ }^{7-10}$ According to the World Health Organization, the term "probiotics" refers to "live microorganisms (that) when administered in adequate amounts confer a health benefit on the host."11 Probiotics have a long history of use in health promotion and are generally considered safe. ${ }^{12}$ Lactobacillus spp. and Bifidobacterium spp. are commonly used probiotic bacteria. ${ }^{13}$ Previous studies have attempted to examine the role of probiotics in various oral diseases, including periodontitis. ${ }^{14}$

Lactobacillus spp. produce antimicrobial substances, such as bacteriocins. Laboratory strains of Lactobacillus reuteri are known to produce an antimicrobial compound called reuterin, which is a low molecular class of bacteriocin. ${ }^{15}$ However, there are no studies on the antibacterial effect of clinical strains of reuterin isolated from L. reuteri, particularly in periodontitis. To fill this research gap, this first study attempted to investigate the antibacterial properties of L. reuteri LC382415 against pathogenic periodontal bacteria. Moreover, we isolated reuterin and examined its activity against pathogenic periodontal biofilms.

\section{Materials and Methods}

\section{Isolation and Purification of Reuterin}

Previous study done by Widyarman and colleagues in 2018 succeeded in isolating an indigenous Indonesian probiotic L. reuteri strain (LC382415) from a healthy young adult after a comprehensive screening assay..$^{16}$ At first we compare the presence of reuterin isolated from $L$. reuteri LC382415 and L. reuteri ATCC 55730 (as a control) with the molecular weight $52 \mathrm{kDa}$.

In this in vitro experimental study, strain $L$. reuteri LC382415 was inoculated on de Man, Rogosa, and Sharpe (MRS) agar plate and incubated in anaerobic conditions at $37^{\circ} \mathrm{C}$ for 72 hours. This colony was then harvested via centrifugation at $4,000 \times \mathrm{g}$ for 10 minutes and washed twice with phosphate-buffered saline (Oxoid) ( $\mathrm{pH} 7.4$ ).

Reuterin was isolated following a protocol used by Chen et al and Spinler et al with some modifications. ${ }^{17,18}$ In brief, an $L$. reuteri $\mathrm{LC} 382415$ culture was harvested at $1.5 \times 10^{10} \mathrm{CFU} / \mathrm{mL}$ and resuspended in $5 \mathrm{~mL}$ of $300-\mathrm{mM}$ glycerol in MRS broth. This inoculum was incubated under anaerobic conditions at $37^{\circ} \mathrm{C}$ for 3 hours. After fermentation, the cells were collected via centrifugation at $4,000 \times \mathrm{g}$ for 10 minutes. The supernatant fraction was filtered using a filter membrane (pore size: $0.22 \mu \mathrm{m}$; Millipore) and stored at $4^{\circ} \mathrm{C}$. The presence of reuterin in the medium was determined by analyzing its molecular weight using sodium dodecyl sulfate-polyacrylamide gel electrophoresis (SDS-PAGE) method. Four concentrations of reuterin $(12.5,25,50$, and $100 \mu \mathrm{g} / \mathrm{mL})$ were prepared using the Bradford method. ${ }^{19}$ The Bradford assay showed a mean reuterin concentration of $208.06 \mu \mathrm{g} / \mathrm{mL}$.

\section{Confirmation of Reuterin by SDS-PAGE}

SDS-PAGE was used to confirm the presence of reuterin in the samples using a protocol published by Costas with modifications. ${ }^{20}$ The polyacrylamide gel was prepared by assembling gel cassettes using clean glass plates. We combined $30 \mathrm{~mL}$ of acrylamide stock solution, $22.5 \mathrm{~mL}$ of separating gel buffer, and $36.15 \mathrm{~mL}$ of deionized water in a side-arm flask and degassed the solution using a vacuum pump for 3 minutes. While the solution was being gently swirled to ensure adequate mixing, $0.9 \mathrm{~mL}$ of $10 \%$ (w/v) SDS stock was added, along with $0.45 \mathrm{~mL}$ of $10 \%$ ammonium peroxydisulfate and $45 \mu \mathrm{L}$ of tetramethylethylenediamine (TEMED). Two gels were poured, delivering $10 \mathrm{~mL}$ volumes of acrylamide/buffer mixture. When the mixture reached $30 \mathrm{~mm}$ from the top of the plates, polytetrafluoroethylene (PTFE)-coated combs were carefully inserted, projecting $35 \mathrm{~mm}$ into the gel cassettes. We prepared a stacking gel mix in a side-arm flask for two gels $(20 \mathrm{~mL})$. This gave a final concentration of $5 \%$ acrylamide. The mixture was subsequently degassed, and $200 \mu \mathrm{L}$ of $10 \%$ (w/v) SDS was then added, along with $100 \mu \mathrm{L}$ of $10 \%$ (w/v) ammonium peroxydisulfate and $20 \mu \mathrm{L}$ of TEMED. PTFE combs were inserted in 15 to 20 wells $25 \mathrm{~mm}$ into the assembly, leaving $10 \mathrm{~mm}$ for the stacking gel. The gel was left to set for 1 hour. The combs were then removed, and the sample wells were washed thoroughly with deionized water and filled with reservoir buffer.

To prepare the sample, we added $10 \mu \mathrm{L}$ of native buffer into $30 \mu \mathrm{L}$ of sample proteins and heated the mixture in a thermoblock machine (BioSan) at $100^{\circ} \mathrm{C}$ for 5 minutes. After that, $20 \mu \mathrm{L}$ of the protein extract was loaded into each well using a micropipette. The gels were then removed from the assembly/pouring stand, placed in a running apparatus, and filled with tank buffer. The gels were electrophoresed at a constant current of $80 \mathrm{~mA}(50 \mathrm{~V}, 30 \mathrm{~W})$ and a constant temperature of $15^{\circ} \mathrm{C}$ for 2 hours. Coomassie Blue staining solutions were then added ${ }^{20}$ Bradford assays were performed to visualize the reuterin bands using a Coomassie Plus Bradford Assay Kit (Thermo Fisher Scientific) according to the manufacturer's instructions. A standard curve was used to determine the protein concentration of each sample. Bovine serum albumin (Thermo Fisher Scientific) was used as a control sample.

\section{Reuterin on Pathogenic Oral Bacterial Biofilms}

The activity of reuterin isolated from L. reuteri LC382415 against oral pathogenic bacterial biofilms was assessed using monospecies and dual-species biofilms of $P$. gingivalis ATCC 33277 and T. denticola ATCC 35405. The bacteria were cultured on Brain Heart Infusion (BHI) (Sigma Aldrich) broth using the anaerobic GasPak jar system and incubated at $37^{\circ} \mathrm{C}$ for 48 hours. ${ }^{21}$ For monospecies biofilms, $200 \mu \mathrm{L}$ of $10^{7}$ $\mathrm{CFU} / \mathrm{mL} P$. gingivalis or T. denticola inoculum was added to 96-well plates. For dual species biofilms, $100 \mu \mathrm{L}$ of $10^{7}$-CFU/ $\mathrm{mL}$ P. gingivalis inoculum and $100 \mu \mathrm{L}$ of $10^{7}-\mathrm{CFU} / \mathrm{mL}$ T. denticola inoculum were added into 96-well plates (NEST). Both monospecies and dual species inocula were incubated under anaerobic conditions at $37^{\circ} \mathrm{C}$ for 48 hours to form biofilms. Four different concentrations of reuterin $(12.5,25,50$, and $100 \mu \mathrm{g} / \mathrm{mL}$ ) were then added to the biofilms to evaluate its antibacterial activity. The effects were assessed at 1, 3, 6, and 
24 hours. ${ }^{22,23}$ Chlorhexidine $0.2 \%$ was used as a positive control. Wells containing biofilms without reuterin were used as negative controls.

\section{Biofilm Examination}

The first examination was conducted using crystal violet analysis. The next examination was conducted using total plate count for enumeration of CFUs.

Crystal violet $(0.5 \% \mathrm{w} / \mathrm{v})$ was added to all wells, incubated for 15 minutes, and then removed. Absolute ethanol $(200 \mu \mathrm{L})$ was also added to all wells to dissolve remaining crystal violet-biofilm complex. Dissolved crystal violet within each well was measured and considered as biofilm mass.

After crystal violet staining procedure, the photos of biofilm mass were observed by Carl Zeiss Primovert Inverted Microscope (Germany) at a 40x objective. Furthermore the absorbance measurements were performed using a microplate reader (SAFAS) at a wavelength of $595 \mathrm{~nm}$. All treatments were performed in independently triplicate experiments.

For the total plate count, after biofilms were washed with PBS and dried at room temperature, the formed biofilm layer at the base of well was collected and diluted 10-fold. Ten microliters of the dilution solution with concentrations of $10^{-4}$ to $10^{-7}$ were poured on each MRS agar medium plate and were incubated anaerobically at $37^{\circ} \mathrm{C}(2 \times 24 \mathrm{~h})$, and then the CFU count was performed manually.

\section{Standard Curve for Absorbance and Biofilm Quantification}

To quantify absorbance (optical density) for bacterial concentration measurement, a standard curve was used to demonstrate the relationship between optical density and colony count, P. gingivalis and T. denticola inocula at $1 \mathrm{Log} 10 \mathrm{CFU} / \mathrm{mL}$ were diluted in BHI (Sigma Aldrich) broth in a 1:10 dilution series to achieve six dilutions $\left(10-10^{6}\right)$ (-Supplementary Fig. S1, available in the online version only). Biofilms were grown under static conditions in sterile 96-well microplates, with each well containing $200 \mu \mathrm{L}$, at $37^{\circ} \mathrm{C}$ for 24 hours. Upon removal from incubation, the biofilms were heat fixed and stained with crystal violet. The absorbance was measured at a 595-nm excitation wavelength. ${ }^{24}$

\section{Statistical Analysis}

The obtained results were statistically analyzed using one-way analysis of variance (ANOVA) to assess differences in biofilm reduction. The level of significance was set to $p$ $<0.05$. The Shapiro-Wilk test was used to assess normality, and Levene's test was used to assess the homogeneity of variance. The statistical analysis was performed using IBM SPSS Statistics version 20 (IBM Corp.) for Windows. ${ }^{25}$

\section{Results}

Isolation of Reuterin, SDS-PAGE, and Bradford Assay The presence of reuterin isolated from $L$. reuteri LC382415 and ATCC 55730 is shown in - Fig. 1. SDS-PAGE of the LC382415 culture supernatants showed a 52-kDa band, confirming the presence of reuterin. ${ }^{26}$

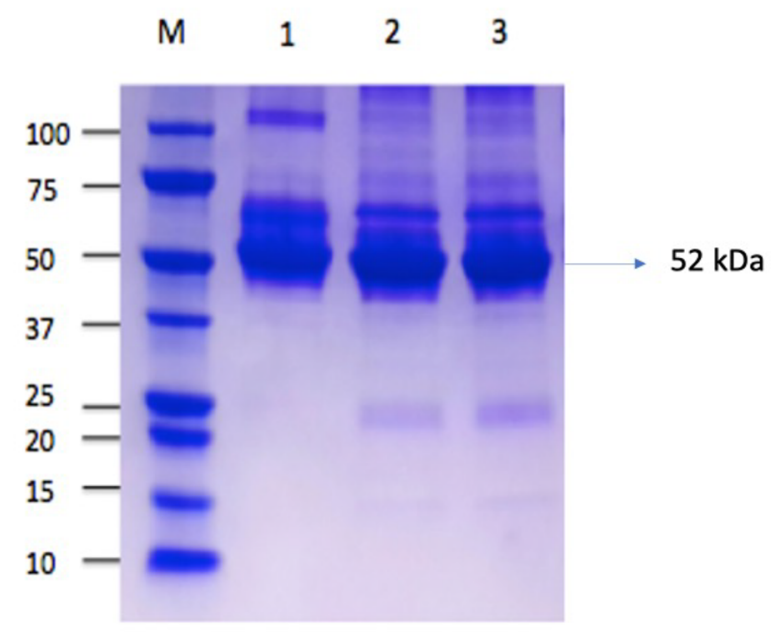

Fig. 1 Reuterin isolate from L. reuteri in 12\% polyacrylamide gel. M, marker protein (molecular weight: 15-100 kDa); bands 1: reuterin isolate from L. reuteri ATCC 55730; bands 2-3: reuterin isolate from Indonesian LC382415 strain (52 kDa).

\section{Activity of Reuterin against Pathogenic Periodontal Biofilms}

The photographs of the biofilm lining 96-well plates of reuterin against each monospecies $P$. gingivalis and $T$. denticola were taken after staining with crystal violet. The biofilms were observed using Carl Zeiss Primovert Inverted Microscope at a 40x objective ( - Figs. 2 and 3 ).

The biofilm assay by using crystal violet showed that reuterin significantly inhibited monospecies $P$. gingivalis and $T$. denticola in dose dependent activity and incubation time. Reuterin in a concentration as low as $12.5 \mu \mathrm{g} / \mathrm{mL}$ significantly inhibited single- and mixed-species biofilms $(p<0.05)$. The most effective of reuterin concentration in the monospecies biofilm of $P$. gingivalis and T. denticola was $100 \mu \mathrm{g} / \mathrm{mL}$ due to which it can inhibit up to 50 and $77 \%$ reduction, respectively, compared with negative control ( - Figs. 4 and $\mathbf{5}$ ) in 1 hour and $100 \mu \mathrm{g} / \mathrm{mL}$ reuterin concentration showed significantly inhibited monospecies of those bacteria in prolonged incubation time compared with negative control. Moreover, reuterin exhibited a significant dose-dependent activity against mixed-species P. gingivalis and T. denticola biofilms in a concentration as low as $12.5 \mu \mathrm{g} / \mathrm{mL}$ (-Fig. 6) within 3 hours. Incubation for up to 24 hours with higher concentrations $(25-100 \mu \mathrm{g} / \mathrm{mL})$ showed an even more significant anti-biofilm activity.

In the total plate count analysis of CFUs, the presence of reuterin isolated from $L$. reuteri LC382415 on each monospecies biofilm of $P$. gingivalis and $T$. denticola showed anti-biofilm activity of concentration-dependent reuterin at various incubation time ( - Figs. $\mathbf{7}$ and $\mathbf{8}$ ).

Overall, there was effect of reuterin to decrease each monospecies biofilm of $P$. gingivalis and $T$. denticola in dose-dependent activity and incubation time.

\section{Discussion}

Periodontal diseases represent a significant health burden, with an estimated annual cost of USD 8 billion, particularly 

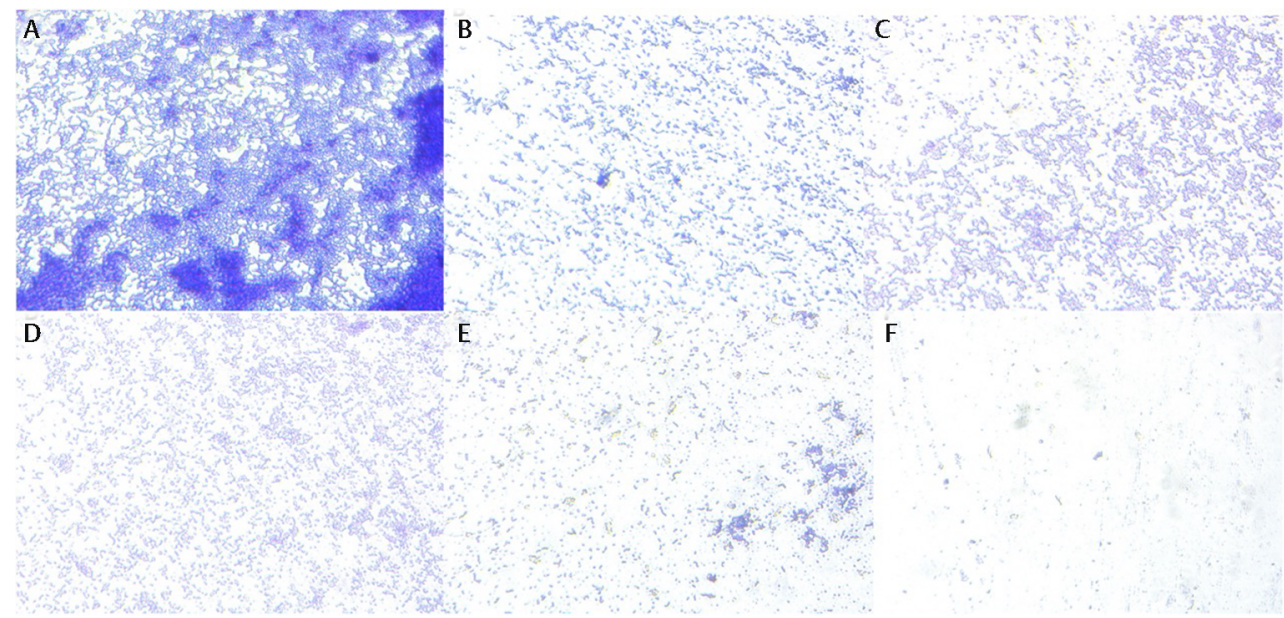

Fig. 2 Inverted optical images of Porphyromonas gingivalis biofilms after treatment with various concentrations of reuterin and control: (A) Treated with bacterial culture medium as a negative control; (B) Treated with $12.5 \mu \mathrm{g} / \mathrm{mL}$ reuterin; (C) Treated with $25 \mu \mathrm{g} / \mathrm{mL}$ reuterin; (D) Treated with $50 \mu \mathrm{g} / \mathrm{mL}$ reuterin; (E) Treated with $100 \mu \mathrm{g} / \mathrm{mL}$ reuterin; (F) Treated with $0.2 \%$ chlorhexidine as a positive control. The biofilms were observed using Carl Zeiss Primovert Inverted Microscope at a 40x objective.

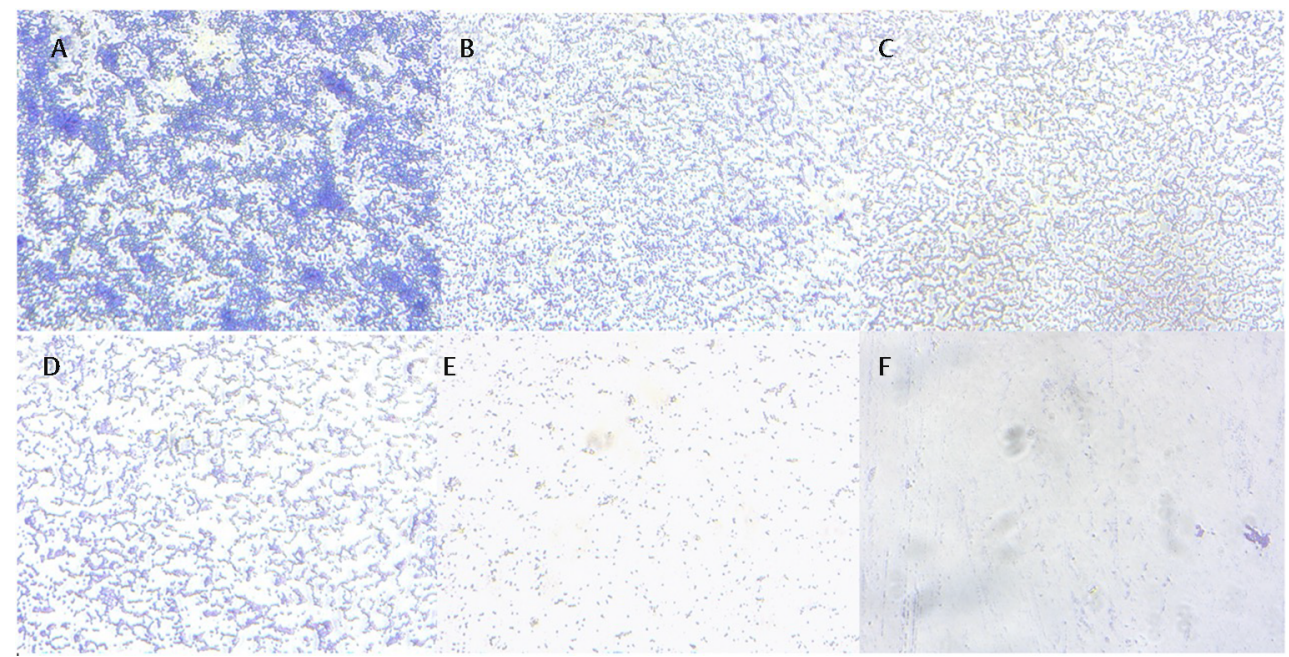

Fig. 3 Inverted optical images of Treponema denticola biofilms after treatment with various concentrations of reuterin and control: (A) Treated with bacterial culture medium as a negative control; (B) Treated with $12.5 \mu \mathrm{g} / \mathrm{mL}$ reuterin; (C) Treated with $25 \mu \mathrm{g} / \mathrm{mL}$ reuterin; (D) Treated with $50 \mu \mathrm{g} / \mathrm{mL}$ reuterin; (E) Treated with $100 \mu \mathrm{g} / \mathrm{mL}$ reuterin; (F) Treated with $0.2 \%$ chlorhexidine as a positive control. The biofilms were observed using Carl Zeiss Primovert Inverted Microscope at a 40x objective.

in Malaysia. ${ }^{27}$ Therefore, considerable efforts have been made to explore new therapeutic strategies against periodontal bacteria. In this study, we found that novel clinical isolates of an indigenous Indonesian L. reuteri strain show promising properties against periodontal pathogens through a reuterin-based mechanism. Importantly, we also found that reuterin can inhibit biofilm formation of periodontal bacteria.

The antimicrobial activity of probiotics is associated with the production of organic acids, peptides (bacteriocins), carbon dioxide, hydrogen peroxide, ethanol, and diacetyl. ${ }^{28}$ Treatment strategies based on probiotics exert antibacterial activities through two mechanisms: (1) inhibition of specific organisms by interfering with adhesion, colonization, and biofilm formation and (2) inhibition of pathogen growth via various substances, such as organic acids, hydrogen peroxide, and bacteriocins. ${ }^{29}$ Through these mechanisms, probiotics can inhibit the growth of dental plaque biofilms, which is in line with the findings of this study. Haukioja, in 2010 reported that patients with gingivitis, periodontitis, and pregnancy gingivitis locally treated with a culture supernatant of an L. acidophilus strain showed significant recovery. ${ }^{30}$ Other studies examining $L$. reuteri strains and L. brevis have also reported improved gingival health, as measured by decreased gum bleeding and inflammation. ${ }^{31-33}$

In this study, we also assessed reuterin efficacy as antibiofilm agent against mixed-species biofilm from two periodontitis-causing bacteria. This is done to mimic the condition of major pathogens that cause periodontitis in vitro. It can be inferred from - Fig. 5 that higher concentration of reuterin better reduces the biofilm mass concentration. It can be postulated that reuterin has the property of 
Effect Reuterin on P. gingivalis

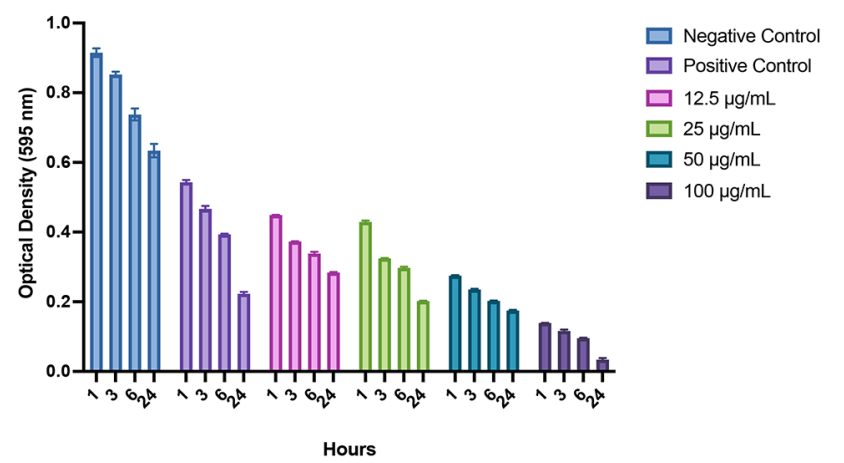

Fig. 4 Graphs showing the inhibition of Porphyromonas gingivalis biofilm growth after treatment with reuterin at different concentrations $(\mu \mathrm{g} / \mathrm{mL})$ and incubation times, as well as comparisons with positive and negative controls. $P$. gingivalis treated with bacterial culture medium as a negative control; $P$. gingivalis treated with $0.2 \%$ chlorhexidine as a positive control. Each graph shows the average of independently triplicate experiments.

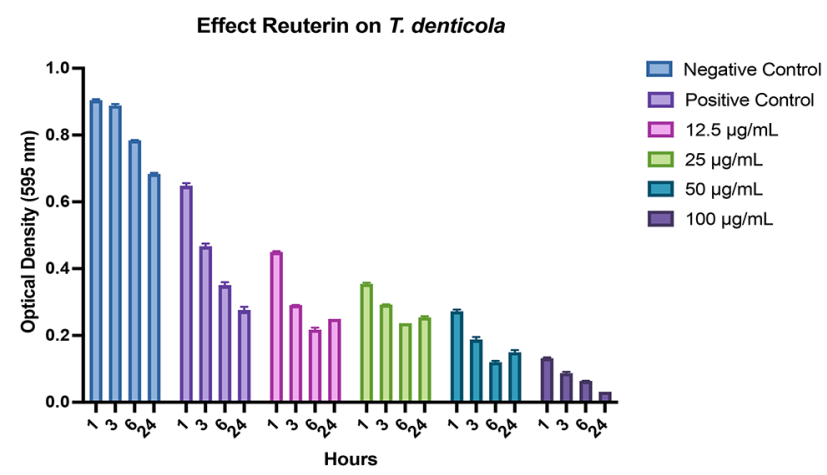

Fig. 5 Graphs showing the inhibition of Treponema denticola biofilm growth after treatment with reuterin at different concentrations $(\mu \mathrm{g} / \mathrm{mL})$ and incubation times, as well as comparisons with positive and negative controls. Treponema denticola treated with bacterial culture medium as a negative control; Treponema denticola treated with $0.2 \%$ chlorhexidine as a positive control. Each graph shows the average of independently triplicate experiments.

antimicrobial effects by inhibiting the production of bacterial ribonucleotide reductase. This is an enzyme that catalyzes the first step in DNA synthesis via competition (HPA-dimer) with ribonucleotides for binding sites or via reaction (3-HPA) with the unstable sulfhydryl groups of ribonucleotide reductase or thioredoxin. This inhibitory activity may explain the broad-spectrum activity of reuterin against periodontal bacteria. ${ }^{34}$ Thus, the higher concentration of the reuterin may give higher efficacy in reducing bacterial biofilm mass. This study provides encouraging evidence for the treatment of periodontal disease using probiotic-derived product, such as reuterin. Further studies are warranted to explore the effect of reuterin in vivo.

\section{Conclusions}

This study is the first to demonstrate the activity of reuterin derived from clinical isolates of $L$. reuteri against monospecies and dual-species periodontal bacterial biofilms. The
Effect of reuterin on mixed-biofilms

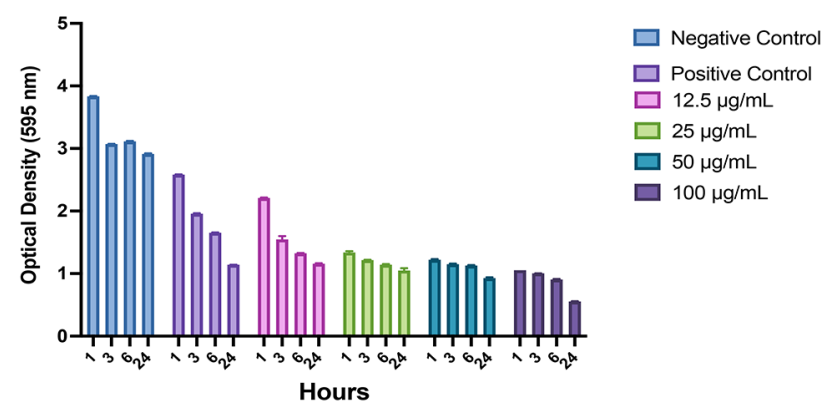

Fig. 6 Graphs showing the inhibition of mixed-biofilm growth after treatment with reuterin at different concentrations $(\mu \mathrm{g} / \mathrm{mL})$ and incubation times, as well as comparisons with positive and negative controls. Each graph shows the average of independently triplicate experiments.

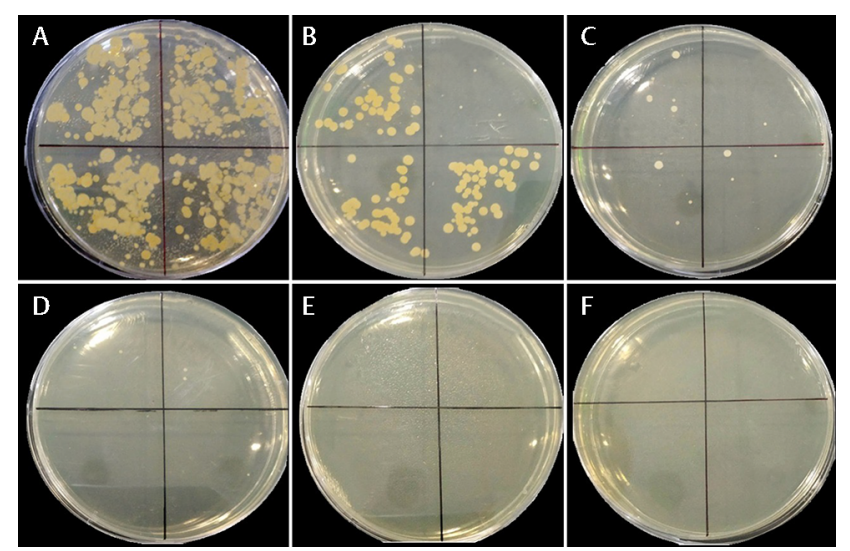

Fig. 7 CFU counts at various incubation times were done to determine the anti-biofilm activity of concentration-dependent reuterin. (A) Porphyromonas gingivalis treated with bacterial culture medium as a negative control; (B) P. gingivalis treated with $12.5 \mu \mathrm{g} / \mathrm{mL}$ reuterin; (C) $P$. gingivalis treated with $25 \mu \mathrm{g} / \mathrm{mL}$ reuterin; (D) $P$. gingivalis treated with $50 \mu \mathrm{g} / \mathrm{mL}$ reuterin; (E) $P$. gingivalis treated with $100 \mu \mathrm{g} / \mathrm{mL}$ reuterin; (F) P. gingivalis treated with $0.2 \%$ chlorhexidine as a positive control.

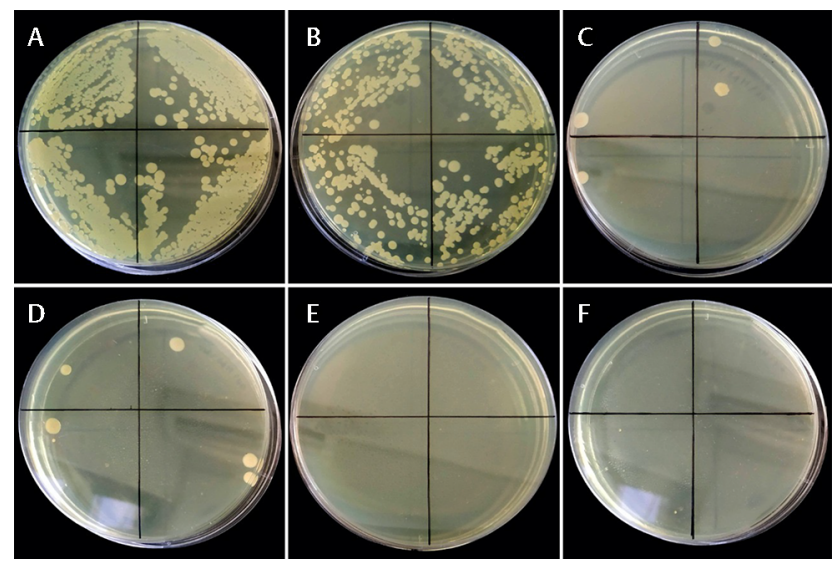

Fig. 8 CFU counts at various incubation times were done to determine the anti-biofilm activity of concentration-dependent reuterin. (A) Treponema denticola treated with bacterial culture medium as a negative control; (B) Treponema denticola treated with $12.5 \mu \mathrm{g} / \mathrm{mL}$ reuterin; (C) Treponema denticola treated with $25 \mu \mathrm{g} / \mathrm{mL}$ reuterin; (D) Treponema denticola treated with $50 \mu \mathrm{g} / \mathrm{mL}$ reuterin; (E) Treponema denticola treated with $100 \mu \mathrm{g} / \mathrm{mL}$ reuterin; (F) Treponema denticola treated with $0.2 \%$ chlorhexidine as a positive control. 
findings could lead to novel therapeutic strategies against periodontitis, benefiting patients worldwide.

\section{Funding}

None.

\section{Authors' Contributions}

A.S.W. contributed toward conceptualization, investigation, and writing an original draft, C.F.T. contributed toward writing-review and editing,

\section{Conflict of Interest}

None declared.

\section{Acknowledgments}

The authors would like to thank the Faculty of Dentistry, Universitas Indonesia, and the Faculty of Dentistry, Trisakti University, for the invaluable support. Furthermore, we want to express our appreciation to Aradhea Monica Drestia, BSc and Stella Pranoto, BSc for their laboratory assistances.

\section{References}

1 World Health Organization. Oral health. Available at: https:// www.who.int/news-room/fact-sheets/detail/oral-health/. Accessed August 24, 2020

2 Kim J, Amar S. Periodontal disease and systemic conditions: a bidirectional relationship. Odontology 2006;94(1):10-21

3 Merchant AT. Periodontitis and dental caries occur together. J Evid Based Dent Pract 2012;12(Suppl 3):18-19

4 How KY, Song KP, Chan KG. Porphyromonas gingivalis: an overview of periodontopathic pathogen below the gum line. Front Microbiol 2016;7:53

5 Reddy MS, Weatherford TW III, Smith CA, West BD, Jeffcoat MK, Jacks TM. Alendronate treatment of naturally-occurring periodontitis in beagle dogs. J Periodontol 1995;66(3):211-217

6 Meisel P, Kocher T. Photodynamic therapy for periodontal diseases: state of the art. J Photochem Photobiol B 2005;79(2):159-170

7 Verna EC, Lucak S. Use of probiotics in gastrointestinal disorders: what to recommend?. Therap Adv Gastroenterol 2010;3(5):307-319

8 Fijan S. Microorganisms with claimed probiotic properties: an overview of recent literature. Int J Environ Res Public Health 2014;11(5):4745-4767

9 Daliri EBM, Lee BH. New perspectives on probiotics in health and disease. Food Sci Hum Wellness 2015;4:56-65

10 Markowiak P, Śliżewska K. Effects of probiotics, prebiotics, and synbiotics on human health. Nutrients 2017;9(9):1021

11 Food and Agriculture Organization of the United Nations, World Health Organization, editors. Probiotics in food: health and nutritional properties and guidelines for evaluation. Rome: Food and Agriculture Organization of the United Nations: World Health Organization; 2006.

12 Raff A, Hunt LC. Probiotics for periodontal health: a review of the literature. J Dent Hyg 2012;86(2):71-81

13 Mahasneh SA, Mahasneh AM. Probiotics: a promising role in dental health. Dent J (Basel) 2017;5(4):26

14 Jayaram P, Chatterjee A, Raghunathan V. Probiotics in the treatment of periodontal disease: a systematic review. J Indian Soc Periodontol 2016;20(5):488-495

15 Ohshima T, Kojima Y, Seneviratne CJ, Maeda N. Therapeutic application of synbiotics, a fusion of probiotics and prebiotics, and biogenics as a new concept for oral candida infections: a mini review. Front Microbiol 2016;7:10
16 Widyarman AS, Pranoto S, Theodorea CF, Bachtiar EW, Bachtiar BM. Isolation and identification of Indonesian Lactobacillus reuteri strain from saliva of young adults. Sci Dent J 2018;2(2):67-75

17 Cleusix V, Lacroix C, Vollenweider S, Le Blay G. Glycerol induces reuterin production and decreases Escherichia coli population in an in vitro model of colonic fermentation with immobilized human feces. FEMS Microbiol Ecol 2008;63(1):56-64

18 Spinler JK, Taweechotipatr M, Rognerud CL, Ou CN, Tumwasorn S, Versalovic J. Human-derived probiotic Lactobacillus reuteri demonstrate antimicrobial activities targeting diverse enteric bacterial pathogens. Anaerobe 2008;14(3):166-171

19 Bradford MM. A rapid and sensitive method for the quantitation of microgram quantities of protein utilizing the principle of protein-dye binding. Anal Biochem 1976;72(1-2):248-254

20 Costas M, The analysis of bacterial proteins by SDS polyacrylamide gel electrophoresis. In: Howard J, Whitcombe DM, eds. Diagnostic Bacteriology Protocols. New Jersey: Humana Press; 1995:27-40

21 Stalons DR, Thornsberry C, Dowell VR Jr. Effect of culture medium and carbon dioxide concentration on growth of anaerobic bacteria commonly encountered in clinical specimens. Appl Microbiol 1974;27(6):1098-1104

22 Christopher AB, Arndt A, Cugini C, Davey ME. A streptococcal effector protein that inhibits Porphyromonas gingivalis biofilm development. Microbiology (Reading) 2010;156(Pt 11): 3469-3477

23 Widyarman AS, Widjaja SB, Idrus E. Strawberry extract's effects on Enterococcus faecalis and Porphyromonas gingivalis biofilms in vitro. Sci Dent J 2017;1:1-5

24 Macaluso A. Characterization of biofilms on medical device materials with application to reusable surgical instruments [dissertation]. South Carolina: Clemson University; 2014

25 SPSS, I. I. B. M. IBM SPSS Statistics for Windows, version 20.0. New York: IBM Corp; 2011:440

26 Talarico TL, Dobrogosz WJ. Purification and characterization of glycerol dehydratase from Lactobacillus reuteri. Appl Environ Microbiol 1990;56(4):1195-1197

27 Mohd Dom TN, Ayob R, Abd Muttalib K, Aljunid SM, Aljunid SM. National economic burden associated with management of periodontitis in Malaysia. Int J Dent 2016;2016:1891074

28 de Oliveira Leite AM, Miguel MAL, Peixoto RS, Rosado AS, Silva JT, Paschoalin VM. Microbiological, technological and therapeutic properties of kefir: a natural probiotic beverage. Braz J Microbiol 2013;44(2):341-349

29 Barzegari A, Kheyrolahzadeh K, Khatibi SMH, Sharifi S, Memar MY, Vahed SZ. The battle of probiotics and their derivatives against biofilms. Infect Drug Resist. 2020;13:659-672.

30 Haukioja A. Probiotics and oral health. Eur J Dent 2010;4(3):348-355

31 Krasse P, Carlsson B, Dahl C, Paulsson A, Nilsson A, Sinkiewicz G. Decreased gum bleeding and reduced gingivitis by the probiotic Lactobacillus reuteri. Swed Dent J 2006;30(2):55-60

32 Twetman S, Derawi B, Keller M, Ekstrand K, Yucel-Lindberg T, Stecksen-Blicks C. Short-term effect of chewing gums containing probiotic Lactobacillus reuteri on the levels of inflammatory mediators in gingival crevicular fluid. Acta Odontol Scand 2009;67(1):19-24

33 Widyarman AS, Drestia AM, Bachtiar EW, Bachtiar BM. The Anti-inflammatory effects of glycerol-supplemented probiotic Lactobacillus reuteri on infected epithelial cells in vitro. Contemp Clin Dent 2018;9(2):298-303

34 Cleusix V, Lacroix C, Vollenweider S, Duboux M, Le Blay G. Inhibitory activity spectrum of reuterin produced by Lactobacillus reuteri against intestinal bacteria. BMC Microbiol 2007;7:101 